\title{
Simulation system for optimizing technical and organizational variants in coalmining production
}

\author{
Sinoviev Vasiliy Valentinovich ${ }^{1,2}$ \\ ${ }^{1}$ Federal Research Center of Coal and Coal Chemistry of \\ SB RAS \\ ${ }^{2}$ T. F. Gorbachev Kuzbass State Technical University \\ Kemerovo, Russia \\ zv150671@gmail.com

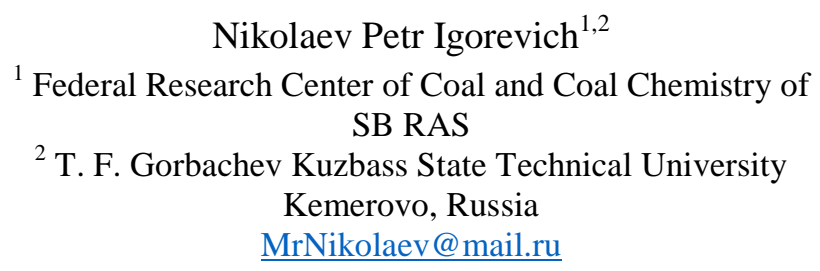

\author{
Starodubov Aleksey Nikolaevich ${ }^{1,2}$ \\ ${ }^{1}$ Federal Research Center of Coal and Coal Chemistry of \\ SB RAS \\ ${ }^{2}$ T. F. Gorbachev Kuzbass State Technical University \\ Kemerovo, Russia \\ $\underline{\text { s_t_an@mail.ru }}$
}

Kuznetsov Igor Sergeevich ${ }^{1,2}$

${ }^{1}$ Federal Research Center of Coal and Coal Chemistry of SB RAS

${ }^{2}$ T. F. Gorbachev Kuzbass State Technical University

Kemerovo, Russia

is150794@mail.ru

\author{
Kravtsov Vladimir Pavlovich ${ }^{1}$ \\ ${ }^{1}$ Federal Research Center of Coal and Coal Chemistry of SB RAS \\ Kemerovo, Russia \\ kravtsov@kemsc.sbras.ru
}

\begin{abstract}
The paper presents a simulating system for choosing an optimal technical and organizational variant of automatized tunneling technology in coalmining production. The system is based on methodology that uses a system-functional approach for tunneling operations analysis and a simulating and evolutionary algorithm for efficiency of evaluation of kits of tunneling automatized mining equipment and choice of an optimal technical and organizational variant by the complex criterion, consisting of minimal time of staying of workers near mine face, minimal unit cost and minimal cycle time of tunneling.
\end{abstract}

Keywords - software, automatization, simulation, coalmining production, evolutionary algorithm.

\section{INTRODUCTION}

In underground coalmining production, an important stage of the engineering part is analysis and synthesis of technical and organizational variants. Stochasticity and dynamism of manufacturing processes complicate implementation of this stage, which makes it difficult to use traditional analytical methods for production decisions. Plenty of automatization opportunities [1], multivariance of ways of production organization, and high cost of technological risk make projecting of coalmining production complicated. At the same, usually, to identify a clear analytical criterion of optimization and constraints of production parameters is difficult or impossible. It stipulates necessity of using methods of algorithmic optimization with an opportunity to identify an optimization criterion value for every technical and organizational variant through simulating [2-5]. In addition, it allows developing a software for detailed exploration of the kit optimization problems. Thus, an actual scientific task is creation of the simulating system for optimization of tunneling technical and organizational variants choice in coalmining production.

\section{THEORETICAL BASIS}

Collective of Coal Institute of Federal Research Center of Coal and Coal Chemistry of SB RAS created a simulating system for optimization of choice of tunneling technical and organizational variants in coalmining production without permanent workers staying near mine face due to production automatization. Figure 1 shows the system interface with external components. 


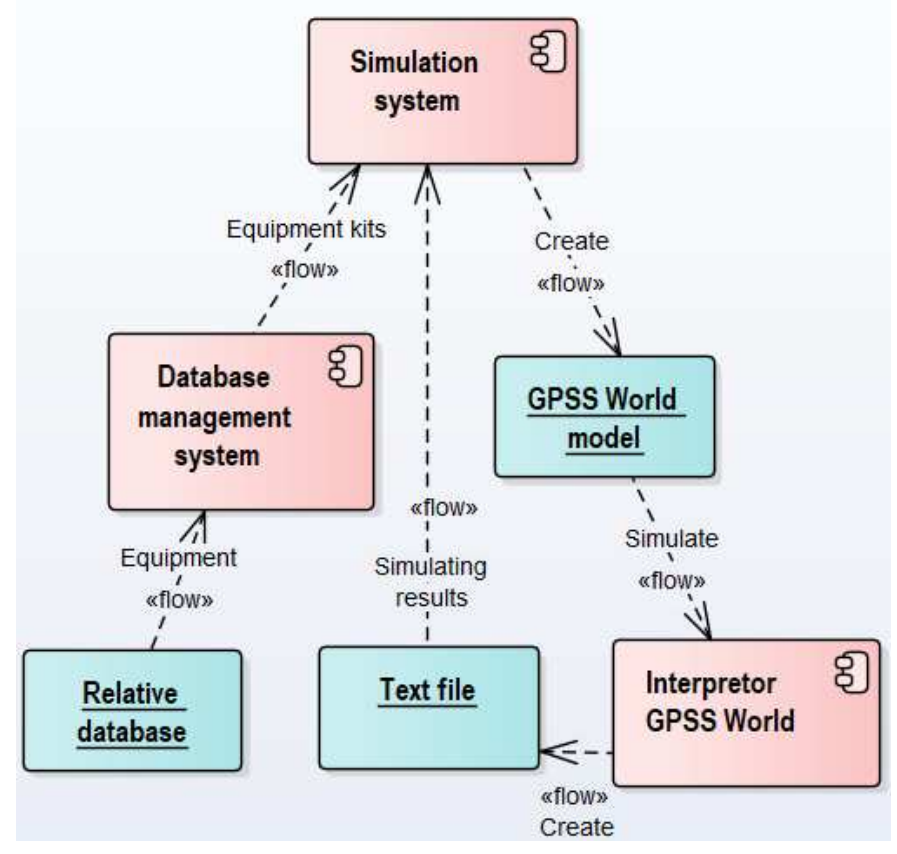

Fig.1. System interface with external components

There are the following external components that interact with system: a relational database for information about mining equipment storage and mining equipment kits compiling; a simulating models interpreter, based on GPSS World simulating language, for work simulation of mining equipment kits; files of simulation models; text files with simulate results for import to the system.

The models' interpreter functions on simulation principles. There are three main approaches to simulating: system dynamics, discrete event modeling, agent-based modeling. System dynamics is useful in long-term, strategic models and takes a high level of abstraction [6-8]. Properties and characteristics of individual elements are not a matter in system dynamics. This approach is used when it is necessary to explore general of quantitative assessments processes only without taking into account the dynamics of individual elements. It is necessary to consider and evaluate dynamics of individual elements and interaction between them in tunneling technology simulating, therefore the use of system dynamics is purposelessly.

In discrete event, modeling system dynamics consists of operations sequence (arriving, delay, resource capture, separation, etc.) with any entities (transactions), representing clients, documents, calls, data packages, vehicles, etc. These entities are passive and don not control their own dynamics, but they can have certain attributes, which have an influence on the process of their servicing (e. g. type of call, complicate of work) or statistics accumulating (average time of waiting, cost). This modeling is used on a medium or low level of abstraction: each object is modeled individually as an individual entity, but many of "physical level" details (geometry, acceleration/deceleration) are not considered [9$11]$.
Agent-based modeling is used when there is no information about relationships between elements of system, but it is known how these elements (agents) acts. In literature [12], there are many definitions of agent-based modeling. From the point of view of practical application, agent-based modeling is a method of simulating, which explores the behavior of decentralized agents and how this behavior determines behavior of the whole system.

Agent model development demands from engineer to enter agent's options (it can be people, companies, assets, projects, machines, cities, animals, etc.), defines their behavior, put them into any environment, defines their possible connections, and after he launches simulating. Individual behavior of each agents creates global behavior of modeling system.

From the modeling point of view, the majority of mining works goes to discrete processes with a final number of conditions: start and final of drilling, rock mass loading and unloading, support advancing, start and final of mining face processing. Functioning of system like that we should consider as consequent changes of conditions of discrete moments of time. System options do not change. A lot of constant processes should be considered as discrete, because it is easier to imitate them. Coal mass, which is on the conveyor, is considered as movement of fixed volumes per time part. Moreover, there is a full opinion about the process and operations sequence in technology.

Paying attention to this fact, discrete event modeling has been chosen for evaluating of technical and organized variants of mining works leading.

Data source for the system is a relational database of equipment, using in coalmining production for tunneling, and its characteristics. In addition, system user defines mining environmental conditions. There are the following relations in the database (fig. 2):

1) Equipment models relation. It contains information about equipment models, price, productivity parameters and average number of workers near mineface for equipment maintenance.

2) Relation of mining equipment compatibility. It is necessary to except compiling of mining equipment, which are physically not supposed to be used mutually (e.g. it's impossible to use an artificial neural network without technical means of space scanning) or irrational (e.g. irrational use rock bolting rig only for drilling and assigning worker to bolt instalation).

3) Production processes relation for various tunneling technologies.

4) Technological operations relation and their belonging to production processes. 


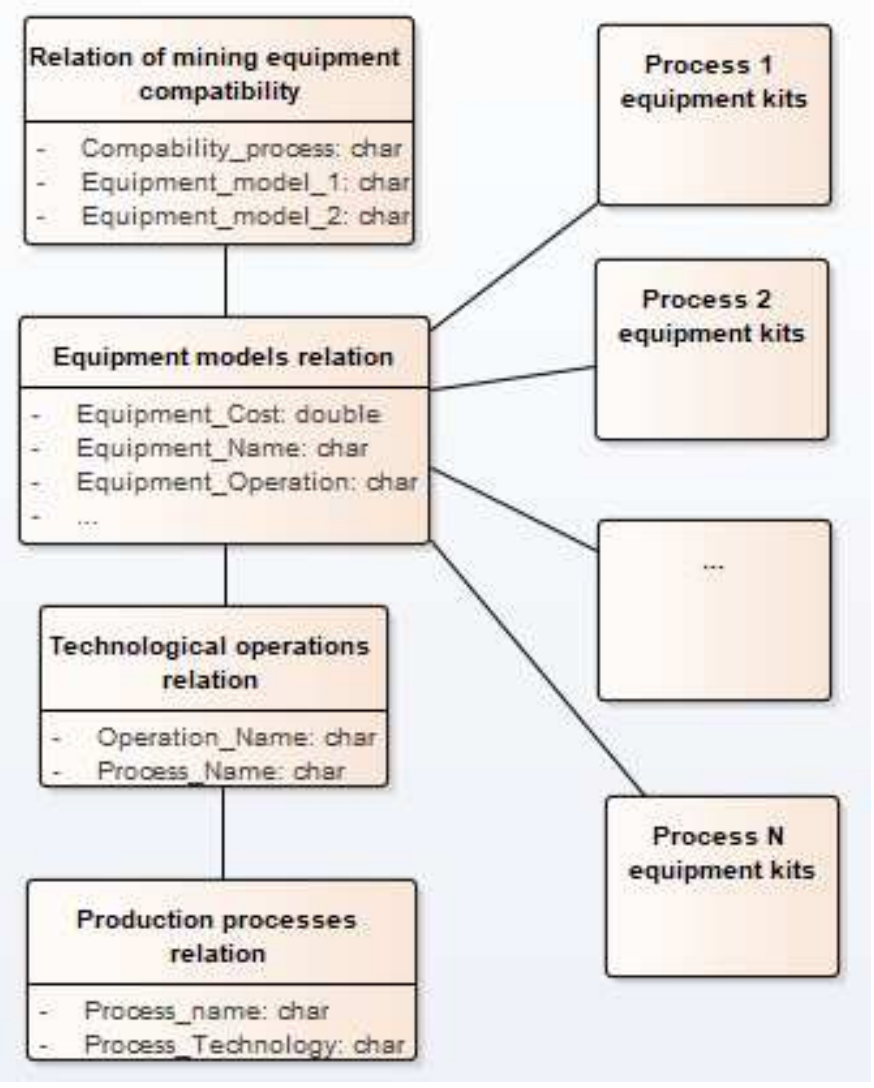

Fig. 2. Database relations diagram

At the first system work stage, let us compile mining equipment kits for every production process using database cursors, which is based on equipment models relation and relation of mining equipment compatibility.

A variety of mining equipment types and its automatization ways makes technically impossible the of use brute-force search for evaluating the mining equipment kits and an optimal choice of them. Therefore, the second stage of system work is based on evolutionary algorithm principles [13-15]. The main class in the evolutionary algorithm is a creature, which is a technical and organizational variant of tunneling. Each creature has chromosomes that contain parameters of using equipment kits for tunneling. Chromosome length equals the production process number used for definite tunneling technology and determined environmental conditions. During evolutionary algorithm functioning, creatures compete with each other for survival. It leads to survival of creatures with superior production parameters. An evolutionary algorithm is arranged in the following scheme (fig. 3):

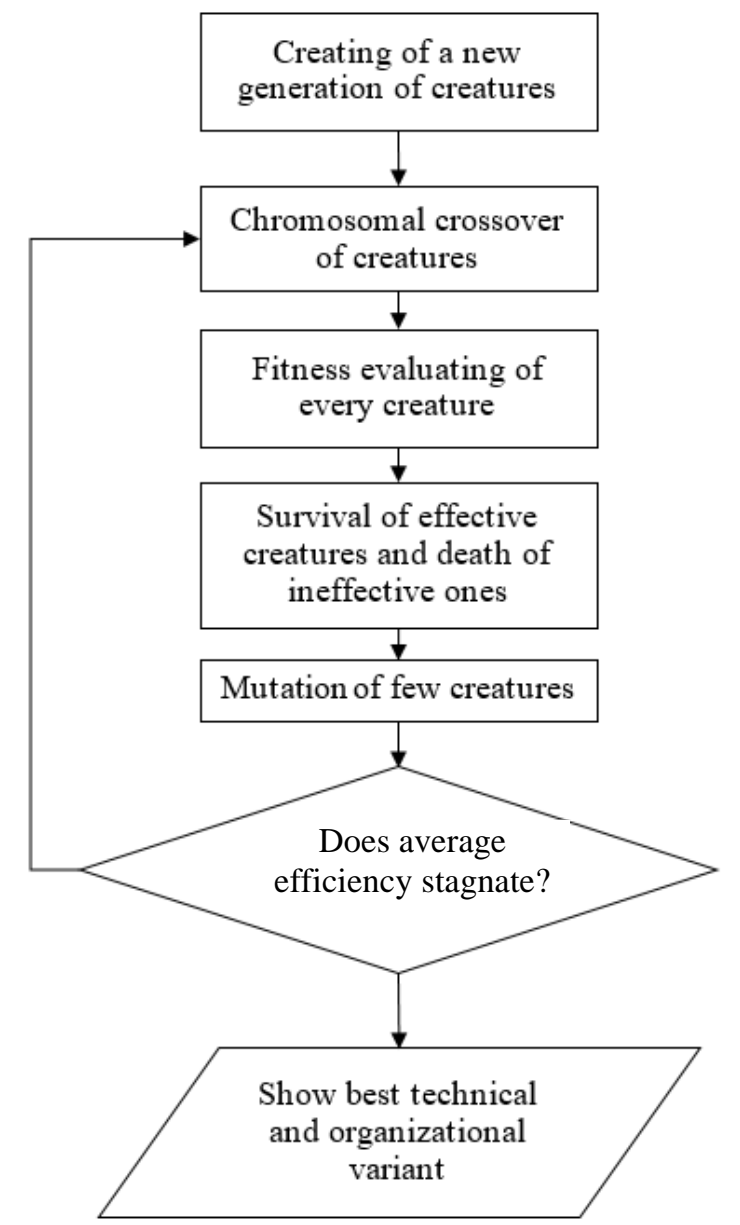

Fig. 3. Scheme of evolutionary algorithm

1) Creating of a new generation of creatures. For each production process in the database, the system builds a generation of creatures with randomly filled chromosome on base mining equipment kits. A user can enter the kit number of creatures in generation. The more creatures are in the generation, the less steps are needed for the algorithm of finding an optimal (suboptimal) technical and organizational tunneling variant, the longer will last every step of the algorithm.

2) Chromosomal crossover of creatures. Available in generation, creatures cross their chromosomes in pairs (calls "parents") with formation of two new creatures (calls "children"). Children have chromosomes, randomly selected from parents. Generation includes newborn children.

3) Fitness evaluating of every creature, which reflects a technical and organizational variant of tunneling. It is two group of methods for creature fitness evaluating: analytical and simulation. Analytical methods have high accuracy and high time consuming. Analytical models are usable for a strictly defined number of modelling objects and difficult to adopt to other objects. In addition, these methods do not register the dynamics and stochastic nature of tunneling. 
Simulation allows getting the satisfactory evaluating (with an error of up to 5\%) with low time consuming, registration of dynamics and stochastic nature of tunneling. The system has been created using simulating language GPSS World for creating simulating models. These models are based on creatures of current generation. Further, through interaction with an external component - interpreter of simulation models - the system simulates tunneling. Simulation models in discrete event simulating language GPSS World contains the following segments: "external conditions determination", "breaking of rock", "rock loading”, "roof support”, "auxiliary works", "calculation of production efficiency and recording it in a text file" and "time countdown". Figure 4 presents the composition of a typical GPSS World segment simulating the work of mining machines. An interpreter of simulation models writes results into text file, and then the system reads it and makes evaluating of main parameters of tunneling based on results - chronological mean of workers staying near the mine face, unit cost of tunneling and cycle time of tunneling.

\begin{tabular}{|c|c|c|}
\hline SAVEVALUE & & $\begin{array}{l}\text { export of mining machine } \\
\text { parameters from database }\end{array}$ \\
\hline SEIZE & MACHINE & $\begin{array}{l}\text { start of mining machine } \\
\text { use }\end{array}$ \\
\hline ADVANCE & & $\begin{array}{l}\text { arrival of a mining } \\
\text { machine to mineface }\end{array}$ \\
\hline SAVEVALUE & & $\begin{array}{l}\text { being near mineface } \\
\text { time countdown }\end{array}$ \\
\hline ADVANCE & & $\begin{array}{l}\text { execution of the } \\
\text { main operation }\end{array}$ \\
\hline SAVEVALUE & & $\begin{array}{l}\text { being near mineface } \\
\text { time countdown }\end{array}$ \\
\hline ADVANCE & & $\begin{array}{l}\text { departure of a mining } \\
\text { machine from mineface }\end{array}$ \\
\hline RELEASE & MACHINE & $\begin{array}{l}\text { end of mining machine } \\
\text { use }\end{array}$ \\
\hline
\end{tabular}

Fig. 4. Typical GPSS World segment simulating mining machine work

4) Survival of effective creatures and death of ineffective ones. All generations, which contain parents and children creatures, sorting by the value of the complex optimality criterion. The best half of them passes into the next generation, the worst half is deleted from the system.

5) Mutation of few creatures. The chromosome of every creature mutates with small random chance - it reflects replacement of one mining equipment kit in the process, coded in the chromosome, to random other kit. This step allows avoiding jamming in local optimum and attaining global optimum to the algorithm with bigger chance.

6) Determination of evolution stop. If the condition "Average efficiency of last $N$ generations stagnates" of the checking result is true, then the algorithm ends its work. As an optimal (suboptimal) variant, the algorithm shows the user one or a few technical and organizational variants, having the best values of the complex optimality criterion. In addition, the algorithm shows parameters of the best variant (variants). The algorithm goes to step two.

\section{RESULTS.}

Efficiency of the created system was proved when it has been applied in existing conditions at the time of production, on Uvalnaja coal mine (Tersinskij geological and economical district of Kemerovo region). The subject of analysis was three inclined opening shafts with a cross-section of $33 \mathrm{~m}^{2}$ in tunneling and the angle of inclination up to $18^{\circ}$ by the drilling and blasting method with a $2 \mathrm{~km}$ total length. In practice, sinking of these shafts by nonautomated equipment had given efficiency indicators: an average number of workers near the mine face -1.78 , cycle time of tunneling $-28.06 \mathrm{~min} / \mathrm{m}^{3}$, unit cost of tunneling $-2300 \mathrm{rub} / \mathrm{m}^{3}$.

The simulation system for optimization of organizational and technical variants of coal mining productions for conditions of tunneling on Uvalnaja coalmine offered a partly automated set of equipment, whose implementation will provide opportunity to attain optimal parameters of production. The kit includes: a drill-loader with shoveling parts, which executes all operations autonomously, excepted detection and access to broken rock mass and also a charging, scaling machine and a rock bolting rig with remote control. The kit application allows one to attain the following parameters: an average number of workers near the mine face -1.07 , cycle time of tunneling $-12.33 \mathrm{~min} / \mathrm{m}^{3}$, unit cost of tunneling $-2778 \mathrm{rub} / \mathrm{m}^{3}$. Wherein, the number of workers near the mine face will decrease by $40 \%$, cycle tunneling time will decrease by $56 \%$ with production cost growth - by $20.8 \%$.

Also the efficiency of the created system was proved for tunneling in Makaryevskoe coalfield (Tersinskij geological and economical district of Kemerovo region). The subject of analysis was preparatory works (building of horizontal roadways with the cross-section of $12-16 \mathrm{~m}^{2}$ in tunneling) by drilling and a blasting method with a $6 \mathrm{~km}$ total length. The resulting kit includes a drill-loader with a ladle, which executes all operations autonomously, except detection, access and scooping of broken rock mass and also a charging, scaling machine and a rock bolting rig with remote control. This kit application allows one to attain the following parameters: an average number of workers near the mine face -1.26 , cycle 
time of tunneling $-14.28 \mathrm{~min} / \mathrm{m}^{3}$, unit cost of tunneling $2846 \mathrm{rub} / \mathrm{m}^{3}$. In comparison with traditional non-automated technology, the number of workers near the mine face will decrease by $34 \%$, cycle tunneling time will decrease by $47 \%$ with production cost growth - by $23.5 \%$.

\section{CONCLUSION.}

The developed system, which is based on the method of the systematic-functional approach in tunneling analysis, as well as the simulating and evolutionary algorithm for efficiency evaluating of tunneling equipment kits and an optimal variant choice by criteria of the minimal average number of workers near the mine face, minimal duration and minimal cost of the sinking cycle, allows one to define technical and organizational variants of tunneling works for coal productions with optimal efficiency indicators.

\section{References}

[1] V. V. Zinov'ev, A. E. Mayorov, A. N. Starodubov, P. I. Nikolaev "System approach to automation and robotization of drivage," IOP Publishing Ltd: IOP Conference Series: Earth and Environmental Science, Vol. 134, 012042.

[2] A. N. Starodubov, V. V. Sinoviev, V. V. Okolnishnikov, Simulation system of mining works, Proceedings of the 28TH European Modeling and Simulation Symposium - 2016, September 26 - 28 2016, Cyprus, pp. 323-327.

[3] J.R. Sturgul, Mine Design: Examples Using Simulation, Soc. of Mining Engr. (USA): Littleton, 2000.

[4] V. L. Konyukh, Strategy of Automation for Underground Mining. IFOST: 2007 international forum on strategic technology, Ulaanbaatar, Mongol People Republic, pp. 615-618, 2007.
[5] V. L. Konyukh, Design of Automated Systems Using Simulation. IFOST 2008, Proceeding of the third international forum on strategic technologies, Novosibirsk, Russia, pp. 431-434, 2008.

[6] Michael R. Goodman, Study Notes in System Dynamics. System dynamics series, Pegasus Communications, 1989.

[7] A. M. Lou, A. D. Kelton, Simulation modeling and analisys, SanktPetersburg, 2004.

[8] V. V. Devytkov, The methodology and technology of simulation studies of complex systems: current status and prospects of development. Monograph, Moscow Vuzovskyj uchebnick, INFRA-M Publ., 2013.

[9] S. V. Klishin, V. I. Klishin, G. Yu. Opruk, Modeling Coal Discharge in Mechanized Steep and Thick Coal Mining, Journal of mining science, Vol. 49, I. 6, 2013, pp. 932-940.

[10] A. Soofastaei, S. M. Aminossadati, M. S. Kizil, A discrete-event model to simulate the effect of truck bunching due to payload variance on cycle time, hauled mine materials and fuel consumption. International journal of mining science and technology, Vol. 26, I. 5, pp. 745-752, 2016.

[11] V. Okolnishnikov, S. Rudometov, S. Zhuravlev, Simulating the Various Subsystems of a Coal Mine, Engineering technology \& applied science research, pp. 993-999, 2016 .

[12] E. Bonabeau, Agent-based modeling: Methods and techniques for simulating human systems, Proceedings of the national academy of sciences of the United States of America, Vol. 99, p. 3, pp. 7280-7287, 2002.

[13] Zitzler, Eckart; Deb, Kalyanmoy; Thiele, Lothar. Comparison of Multiobjective Evolutionary Algorithms: Empirical Results. Evolutionary computation. V. 8. I. 2. 2000. P. 173-195.

[14] Zhang Qingfu, Li Hui, MOEA/D: A multiobjective evolutionary algorithm based on decomposition, Ieee transactions on evolutionary computation, Vol. 11, I. 6, pp. 712-731, 2007.

[15] Carlos M.Fonseca, J. Peter Fleming "An Overview of Evolutionary Algorithms in Multiobjective Optimization," Evolutionary computation, Vol. 3, I. 1, pp. 1-16, 1995. 